\title{
Features of the Thermolysis of Aromatic Compounds
}

\author{
D. A. Zherebtsov ${ }^{a}$, , S. A. Nayfert ${ }^{a}$, M. A. Polozov ${ }^{a}$, and R. S. Morozov ${ }^{a}$ \\ ${ }^{a}$ South Ural State University, Chelyabinsk, 454080 Russia \\ *e-mail: zherebtsov_da@yahoo.com \\ Received May 17, 2021; revised May 17, 2021; accepted May 24, 2021
}

\begin{abstract}
The effect of structure of 25 aromatic compounds on the morphology of carbon formed from them during heating to a temperature of $970^{\circ} \mathrm{C}$ in an inert atmosphere is studied. The specific surface area is determined for a number of products via nitrogen adsorption $\left(28-48 \mathrm{~m}^{2} / \mathrm{g}\right)$. Several aromatic compounds are shown to form carbon without melting stage. X-ray phase analysis nevertheless confirms the formation of just amorphous carbon in all cases, and a negligible amount of graphite in amorphous carbon in only two cases. The thermolysis of a number of compounds is studied via synchronous thermal analysis. It is shown that slow heating during thermolysis can reduce the temperatures of transformation by tens of degrees and even alter the nature of thermolysis.
\end{abstract}

Keywords: aromatic compounds, carbon, thermolysis

DOI: $10.1134 / \mathrm{S} 0036024421120232$

\section{INTRODUCTION}

Carbon materials differ over a wide range of properties, depending on their structure. Crystalline forms of carbon are currently limited to diamond (and its hexagonal modification, lonsdaleite), graphite, and several fullerenes. However, hypothetical structures of new carbon materials were proposed as early as the first half of the 20th century [1]. Roald Hoffmann, a Nobel Laureate in Quantum Chemistry, later proposed structures for tetragonal forms of carbon, in which carbon atoms with only $s p^{2}$ - or alternately $s p^{2}$ - and $s p^{3}$-hybridized orbitals are arranged orderly $[2,3]$. Such structures have become a favorite object of calculations by quantum chemists [4], but none of these structures have been obtained experimentally. Modern trends in chemistry aimed at organic electronics have led to the discovery of such planar and linear carbon materials as crystalline polymers obtained via the polymerization of crystalline diacetylene monomers [5], including graphene nanoribbons obtained via the thermolysis of crystals of diacetylene compounds in the range of $400-600^{\circ} \mathrm{C}[6]$.

The thermolysis of a number of polymers (e.g., phenol-formaldehyde and furan resins, polyvinyl chloride, polyvinylidene fluoride, polyvinyl alcohol, and cellulose) can lead to the formation of amorphous carbon. Due to their ability to form rigid cross-linked polymers that retain their shape during thermolysis, and to decompose with high (60-65\%) yields of carbon and relatively low shrinkage (19-22\%), phenolformaldehyde resins are widely used in the manufacture of glassy carbon products (e.g., crucibles, cups, electrodes, and pipes). The thermolysis of some pitches that are multicomponent mixtures of heavy polycyclic aromatic compounds results in the forma- tion of graphite. In all cases, there is an intense series of polycondensation reactions that produce glassy carbon (GC) or graphite in the interval of $400-500^{\circ} \mathrm{C}$.

A rise in the melting point of crystalline polycyclic aromatic compounds to $500^{\circ} \mathrm{C}$ (which occurs, for example, upon an increase in the number of cycles in a molecule) would be expected to result in the onset of decomposition (for example, via dehydrocondensation) of such a compound in the solid state. This could produce carbon retaining the main features of the structure of the initial compound's molecular crystal.

Studies of the thermolysis of coronene and dicoronylene have shown that the former melts at $427^{\circ} \mathrm{C}$, while the latter decomposes without passing into a molten state. However, both compounds form amorphous carbon at temperatures above $550^{\circ} \mathrm{C}$ [7]. It was reported in [8] that the carbonization of dicoronylene in the solid state (without melting) during slow heating $\left(1^{\circ} \mathrm{C} / \mathrm{min}\right.$ to $\left.1000^{\circ} \mathrm{C}\right)$, or with melting at $600-700^{\circ} \mathrm{C}$ during fast heating $\left(1 \mathrm{~min}\right.$ to $\left.1000^{\circ} \mathrm{C}\right)$, in both cases formed coke with a certain ordering, according to data from optical polarized light microscopy. However, the authors did not provide diffractograms of the products to support their assumption of a graphite-like structure.

In contrast, studies on the products of isoviolanthrone and hexaiodobenzene thermolysis [1], and of the products of thermolysis of different metal-organic frameworks [9] or metal carboxylates [10, 11], revealed the formation of only X-ray amorphous carbon. Authors who obtained graphene nanoribbons at $600^{\circ} \mathrm{C}$ also did not report whether graphite formed from them at higher temperatures [6]. 
Table 1. Aromatic compounds used for thermolysis

\begin{tabular}{|c|c|c|c|c|}
\hline No. & Trivial/nomenclature name & Molecular formula & Purity & $\begin{array}{l}\text { Means of } \\
\text { thermolysis }\end{array}$ \\
\hline 1 & $\begin{array}{l}\text { Thioindigo bright pink } \mathrm{ZhD} / 4,4 \text { '-dimethyl-6,6'-dichlorothio- } \\
\text { indigo }\end{array}$ & $\mathrm{C}_{18} \mathrm{H}_{10} \mathrm{O}_{2} \mathrm{~S}_{2} \mathrm{Cl}_{2}$ & $\begin{array}{l}\text { Technical grade, } \\
\text { reagent grade }\end{array}$ & M, DSC \\
\hline 2 & Vat bright green SD/ Dimethoxyviolanthrone & $\mathrm{C}_{36} \mathrm{H}_{20} \mathrm{O}_{4}$ & Technical grade & M \\
\hline 3 & Vat scarlet $2 \mathrm{ZhD} / \mathrm{a}$ mixture of cis- and trans-perinone & $\mathrm{C}_{26} \mathrm{H}_{12} \mathrm{O}_{2} \mathrm{~N}_{4}$ & Technical grade & M, DSC \\
\hline 4 & Vat Bordeaux D/cis-perinone & $\mathrm{C}_{26} \mathrm{H}_{12} \mathrm{O}_{2} \mathrm{~N}_{4}$ & $\begin{array}{l}\text { Technical grade, } \\
\text { reagent grade }\end{array}$ & M, DSC \\
\hline 5 & Vat bright orange $\mathrm{KKhD} / 10$-dibromantanthrone & $\mathrm{C}_{22} \mathrm{H}_{8} \mathrm{O}_{2} \mathrm{Br}_{2}$ & $\begin{array}{l}\text { Technical grade, } \\
\text { reagent grade }\end{array}$ & M, DSC \\
\hline 6 & Vat golden yellow ZhKhD/3,4,8,9-dibenzopyrenequinone-5,10 & $\mathrm{C}_{24} \mathrm{H}_{12} \mathrm{O}_{2}$ & $\begin{array}{l}\text { Technical grade, } \\
\text { reagent grade }\end{array}$ & M, DSC \\
\hline 7 & Vat bright purple KD/dichloroisoviolanthrone & $\mathrm{C}_{34} \mathrm{H}_{14} \mathrm{O}_{2} \mathrm{Cl}_{2}$ & Technical grade & M, DSC \\
\hline 8 & Vat orange $\mathrm{D} /$ trans-perinone & $\mathrm{C}_{26} \mathrm{H}_{12} \mathrm{O}_{2} \mathrm{~N}_{4}$ & Technical grade & M \\
\hline 9 & Vat bright blue ZD & & Technical grade & M \\
\hline 10 & Vat turquoise $2 \mathrm{ZD} /$ indanthrone & $\mathrm{C}_{28} \mathrm{H}_{14} \mathrm{~N}_{2} \mathrm{O}_{4}$ & Technical grade & M \\
\hline 11 & Xylenol orange & $\mathrm{C}_{31} \mathrm{H}_{32} \mathrm{~N}_{2} \mathrm{O}_{13} \mathrm{~S}$ & Analytical grade & M \\
\hline 12 & Phenolphthalein & $\mathrm{C}_{20} \mathrm{H}_{14} \mathrm{O}_{4}$ & Analytical grade & M, DSC \\
\hline 13 & Thymolphthalein & $\mathrm{C}_{28} \mathrm{H}_{30} \mathrm{O}_{4}$ & Analytical grade & M \\
\hline 14 & Bromothymol blue & $\mathrm{C}_{27} \mathrm{H}_{28} \mathrm{Br}_{2} \mathrm{O}_{5} \mathrm{~S}$ & Analytical grade & M \\
\hline 15 & Bromophenol blue & $\mathrm{C}_{19} \mathrm{H}_{10} \mathrm{Br}_{4} \mathrm{O}_{5} \mathrm{~S}$ & Analytical grade & M \\
\hline 16 & Crystal violet & $\mathrm{C}_{25} \mathrm{H}_{30} \mathrm{ClN}_{3} \cdot 9 \mathrm{H}_{2} \mathrm{O}$ & Analytical grade & M \\
\hline 17 & Phenylfluorone & $\mathrm{C}_{19} \mathrm{H}_{12} \mathrm{O}_{5}$ & Analytical grade & M, DSC \\
\hline 18 & Aluminon & $\mathrm{C}_{22} \mathrm{H}_{23} \mathrm{~N}_{3} \mathrm{O}_{9}$ & Analytical grade & $\mathrm{M}, \mathrm{DSC}$ \\
\hline 19 & Methyl orange & $\mathrm{C}_{14} \mathrm{H}_{14} \mathrm{~N}_{3} \mathrm{O}_{3} \mathrm{SNa}$ & Analytical grade & M, DSC \\
\hline 20 & Alizarin red S & $\mathrm{C}_{14} \mathrm{H}_{7} \mathrm{O}_{7} \mathrm{SNa}$ & Analytical grade & M \\
\hline 21 & Methylene blue & $\mathrm{C}_{16} \mathrm{H}_{18} \mathrm{ClN}_{3} \mathrm{~S} \cdot 3 \mathrm{H}_{2} \mathrm{O}$ & Analytical grade & M, DSC \\
\hline 22 & Congo red & $\mathrm{C}_{32} \mathrm{H}_{22} \mathrm{~N}_{6} \mathrm{Na}_{2} \mathrm{O}_{6} \mathrm{~S}_{2}$ & Analytical grade & M \\
\hline 23 & Petroleum pitch & $\mathrm{C}_{50} \mathrm{H}_{47} \mathrm{~N}_{1} \mathrm{O}_{2}$ & Technical grade & M \\
\hline 24 & 1,4-Diphenylbutadiyne-1,3 & $\mathrm{C}_{16} \mathrm{H}_{10}$ & Reagent grade & DSC \\
\hline 25 & 1,6-Bis(bromohexyl)-2,3,7,8-dibenzopyrene-1,6-quinol [12] & $\mathrm{C}_{36} \mathrm{H}_{36} \mathrm{O}_{2} \mathrm{Br}_{2}$ & Reagent grade & DSC \\
\hline
\end{tabular}

Means of thermolysis: M, in a muffle furnace; DSC, in a thermal analyzer furnace.

In this work, we studied the thermolysis of 24 crystalline aromatic compounds in an inert atmosphere up to temperatures of $700-1100^{\circ} \mathrm{C}$.

\section{EXPERIMENTAL}

Thermolysis was performed in two ways: heating in a muffle furnace (the main series of 23 substances) and in a simultaneous thermal analyzer (13 substances). Crystalline aromatic compounds (vat dyes), a number of aromatic indicators, and petroleum pitch were used as the initial materials for thermolysis (Table 1, Fig. S1).

Thermolysis in a muffle furnace was done in a charcoal backfill, using a corundum container common to all samples and containing 22 crucibles with individual solid aromatic compounds (i.e., dyes) and indicators weighing 50-150 mg (Table 1, first 22 samples). Petroleum pitch was processed separately as a mixture of polycyclic aromatic hydrocarbons, according to a similar (but half as fast) procedure. This means of thermal treatment guaranteed a reducing atmosphere around the samples that consisted mainly of nitrogen, $\mathrm{CO}_{2}, \mathrm{CO}, \mathrm{H}_{2}$, water vapor, and other products of the decomposition of organic compounds.

The muffle furnace was heated from 20 to $600^{\circ} \mathrm{C}$ over $50 \mathrm{~h}\left(0.2^{\circ} \mathrm{C} / \mathrm{min}\right)$, and then from 600 to $970^{\circ} \mathrm{C}$ over $2 \mathrm{~h}$, followed by switching off and cooling with the furnace.

The second means of thermolysis was heating a number of samples (mainly those that had no signs of melting after thermolysis in a muffle furnace) weighing 5-8 mg, inside a Netzsch 449C Jupiter simultane- 
ous thermal analyzer furnace. Heating was in this case done from 600 to $1100^{\circ} \mathrm{C}$ at a rate of $10^{\circ} \mathrm{C} / \mathrm{min}$ in an argon atmosphere, with simultaneous recording of thermogravimetry (TG) and differential scanning calorimetry (DSC) curves. Technical vat dyes were purified prior to thermal analysis via recrystallization or sublimation, thereby raising their purity to at least reagent grade. In Table 1, technical grade refers to muffle furnace thermolysis; reagent grade, to thermolysis in the thermal analyzer furnace.

The morphology of the resulting samples was investigated at magnifications of up to $\times 20000$ via scanning electron microscopy on a Jeol JSM-7001F microscope. A Rigaku Ultima IV powder X-ray diffractometer was used for the X-ray phase analysis of the products of thermolysis. Several samples were analyzed via low temperature nitrogen adsorption on an ASAP 2020 surface and porosity analyzer.

\section{RESULTS AND DISCUSSION}

All substances during thermolysis in a muffle furnace yielded large amounts of carbon, from 34 to $81 \mathrm{wt} \%$ (Table 2). Optical microscopy allowed us to identify samples with clear signs of melting (meniscus, drops, and glassy carbon foam) and others that retained a powdery state or the shape of needle crystals after thermolysis (Table 2). When viewed through an optical microscope, samples 1-10, 17, and 19-22 were free-flowing powders. Samples 11-16 more or less melted strongly: samples $\mathbf{1 2}$ and $\mathbf{1 6}$ had the form of foam with large, thin-walled bubbles; samples 11, 13, and 14 were foam with medium-sized, thin-walled bubbles; and samples $\mathbf{1 5}$ and $\mathbf{1 8}$ melted and sintered, forming a mechanically strong foam of small bubbles. Sample 13 fell off the crucible walls easily, exposing white corundum, signifying poor adhesion of the sample to corundum and its strong shrinkage. Since shrinkage correlates with weight loss, this was confirmed for sample $\mathbf{1 3}$ (Table 2). In addition to signs of melting visible through a microscope, the melting peak on the DSC curve is evidence of the formation of a liquid phase during heating (Fig. S2, Table 2).

The morphology of the samples was examined at magnifications of up to $\times 50000$ to reveal signs of melting (Fig. 1). The majority of samples 1-10, 17, and 19-22, which were slowly heated in a muffle furnace, showed no signs of melting, according to either optical or electron microscopy data. The morphology of the particles of these samples after thermolysis in a muffle furnace coincides with that of the particles of the initial materials. For example, technical vat dyes are produced in the form of granules (sometimes porous) with diameters of 5-50 $\mu \mathrm{m}$. An interesting feature of samples 5 and $\mathbf{7}$ is the growth of a noticeable amount of carbon nanotubes on their surface during thermolysis (Fig. 1). Since no tubes formed from recrystallized sample $\mathbf{5}$ taken for thermal analysis, we may assume they appeared due to iron impurities.
At higher heating rates in the furnace of the thermal analyzer, most of the samples showed signs of melting, indicated by both microscopic data (Fig. 2) and the melting peak on the thermogram (Fig. S2). When analyzing these thermograms, it should be noted that at temperatures $20-100^{\circ} \mathrm{C}$ below the melting point, sublimation normally becomes noticeable in the form of a gradual acceleration of weight loss on the TG curve. Note that sublimation in ampoules is widely used to grow single crystals of vat dyes. Evaporation usually accelerates upon further heating above the melting point, as was reflected in the form of a gentle but more rapid weight loss. Of course, decomposition in the solid phase and in a melt also contribute to the weight loss, but more often they appear as a sharper step immediately after the melting peak. Samples 1, 5, and 7 were the only ones that showed no signs of melting according to either microscopic or thermoanalytical data. They all characteristically have chlorine or bromine atoms in the aromatic nucleus.

The effect of the heating rate was studied in more detail for samples 6, 17, 19, and 21. Crystalline phenylfluorone melts (Fig. S2) at around $437^{\circ} \mathrm{C}$ (according to Internet data, above $300^{\circ} \mathrm{C}$ ) when heated in a thermal analyzer at a rate of $10^{\circ} \mathrm{C} / \mathrm{min}$, the consequences of which can be observed both by microscopy and with the naked eye (Fig. 2). After heating to $406^{\circ} \mathrm{C}$ and holding at this temperature for $2 \mathrm{~h}$, the crystals become black, samples lose a considerable part of their mass, and the powder diffractogram takes the form of a halo with traces of phenylfluorone reflections. Using the ratio of the halo area and phenylfluorone reflections, we can estimate the remaining amount of the latter in such a sample as 10$20 \mathrm{wt} \%$. After such thermal treatment, the sample is heated from 406 to $500^{\circ} \mathrm{C}$ at a rate of $0.5^{\circ} \mathrm{C} / \mathrm{min}$, and then to $1000^{\circ} \mathrm{C}$ at a rate of $10^{\circ} \mathrm{C} / \mathrm{min}$. The thermogram shows no signs of melting, and electron microscopy confirms the retention of needle crystals of phenylfluorone in the form of shells filled with carbon material. A distinctive feature is a texture of loose carbon layers less than $100 \mathrm{~nm}$ thick inside the destroyed crystals (Fig. 1). These layers running across the long axis of the needles show that adjacent molecules in phenylfluorone all had a certain dominant direction of condensation with neighboring molecules. The product of thermolysis was nevertheless X-ray amorphous and had no reflections in the diffractogram (Fig. 3). This shows there was no crystal ordering in the packing of carbon atoms even at distances of $0.5-1 \mathrm{~nm}$. The sublimation of a noticeable part of the initial sample was confirmed by a characteristic glassy carbon spot formed on the inner side of the lid of the thermal analysis crucible near the vent hole.

Sample 17 (along with samples 5 and 21, which also had developed porosity according to electron microscopy data after thermolysis in a muffle furnace) was studied via low-temperature nitrogen adsorption (Fig. 4). The BET specific surface area was noticeable 
Table 2. Results from thermolysis

\begin{tabular}{|c|c|c|c|c|c|}
\hline No. & $\begin{array}{l}\text { Signs of melting* after } \\
\text { thermolysis in a muffle } \\
\text { furnace }\left(0.2^{\circ} \mathrm{C} / \mathrm{min}\right)\end{array}$ & $\begin{array}{l}\text { Melting peak on } \\
\text { thermogram, }{ }^{\circ} \mathrm{C} \\
\left(10^{\circ} \mathrm{C} / \mathrm{min}\right)\end{array}$ & $\begin{array}{c}\text { GC residue after thermolysis } \\
\text { in a DSC furnace, wt } \%\left({ }^{\circ} \mathrm{C}\right) \\
\text { at } 10^{\circ} \mathrm{C} / \mathrm{min} \text {, reagent grade }\end{array}$ & $\begin{array}{l}\text { GC residue after } \\
\text { thermolysis in } \\
\text { a muffle furnace } \\
\text { at } 970^{\circ} \mathrm{C} \text {, wt } \%\end{array}$ & $\begin{array}{l}\text { Expected GC } \\
\text { residue, wt \% }\end{array}$ \\
\hline 1 & No & No & $38.9(680)$ & 59.9 & 48.9 \\
\hline 2 & No & - & - & 81.2 & 79.1 \\
\hline 3 & No & Yes, 468 & $55.7(1100)[13]$ & 64.3 & 69.9 \\
\hline 4 & No & Yes, 471 & $39.2(680)$ & 64.6 & 69.9 \\
\hline 5 & No & No & $\begin{array}{l}33.8\left(1000,10^{\circ} \mathrm{C} / \mathrm{min}\right) \\
28.8\left(1000,1^{\circ} \mathrm{C} / \mathrm{min}\right)\end{array}$ & 68.1 & 56.9 \\
\hline 6 & No & $\begin{array}{l}\text { Yes, } 375\left(10^{\circ} \mathrm{C} / \mathrm{min}\right) \\
\text { Yes, } 377\left(1^{\circ} \mathrm{C} / \mathrm{min}\right)\end{array}$ & $\begin{array}{l}21.4\left(1000,10^{\circ} \mathrm{C} / \mathrm{min}\right)[14] \\
10.6\left(1000,1^{\circ} \mathrm{C} / \mathrm{min}\right)\end{array}$ & 74.2 & 86.7 \\
\hline 7 & No & No & $63.8(1000)$ & 78.4 & 77.7 \\
\hline 8 & No & - & - & 64.1 & 69.9 \\
\hline 9 & No & - & - & 73.4 & \\
\hline 10 & No & - & - & 73.9 & 75.9 \\
\hline 11 & Yes & - & - & 49.0 & 46.4 \\
\hline 12 & Yes & Yes, 263 & $37.7(1000)$ & 54.2 & 52.8 \\
\hline 13 & Yes & - & - & 40.6 & 39.0 \\
\hline 14 & Yes & - & - & 40.9 & 38.4 \\
\hline 15 & Yes & - & - & 36.9 & 34.0 \\
\hline 16 & Yes & - & - & 34.3 & 33.7 \\
\hline 17 & No & $\begin{array}{l}\text { Yes, } 437\left(10^{\circ} \mathrm{C} / \mathrm{min}\right) \\
\text { Yes, } 414\left(1^{\circ} \mathrm{C} / \mathrm{min}\right)\end{array}$ & $\begin{array}{l}52.2\left(1000,10^{\circ} \mathrm{C} / \mathrm{min}\right) \\
30.0\left(1000,1{ }^{\circ} \mathrm{C} / \mathrm{min}\right)\end{array}$ & 56.7 & 52.5 \\
\hline 18 & Yes & Yes, 218 & $31.1(1000)$ & 40.3 & 48.2 \\
\hline 19 & No & $\begin{array}{l}\text { Yes, } 369^{* *}\left(10^{\circ} \mathrm{C} / \mathrm{min}\right) \\
\text { Yes, } 329^{* *}\left(1^{\circ} \mathrm{C} / \mathrm{min}\right)\end{array}$ & $\begin{array}{l}26.7\left(1000,10^{\circ} \mathrm{C} / \mathrm{min}\right) \\
20.6\left(1000,1{ }^{\circ} \mathrm{C} / \mathrm{min}\right)\end{array}$ & 69.7 & 38.8 \\
\hline 20 & No & - & - & 38.1 & 35.3 \\
\hline 21 & No & $\begin{array}{l}\text { Yes, } 175\left(10^{\circ} \mathrm{C} / \mathrm{min}\right) \\
\text { Yes, } 157\left(1^{\circ} \mathrm{C} / \mathrm{min}\right)\end{array}$ & $\begin{array}{l}44.9\left(1000,10^{\circ} \mathrm{C} / \mathrm{min}\right) \\
34.6\left(1000,1{ }^{\circ} \mathrm{C} / \mathrm{min}\right)\end{array}$ & 52.3 & 38.6 \\
\hline 22 & No & - & - & 60.1 & 50.2 \\
\hline 23 & Yes & - & $55(800)[15]$ & 77 & 86.6 \\
\hline 24 & - & Yes, 88 & $29.1(900)$ & - & 95.0 \\
\hline 25 & - & Yes, 291 & $47.7(1100)$ & - & 43.6 \\
\hline
\end{tabular}

* Signs of melting after thermolysis in a muffle furnace, according to optical and electron microscope data. **Exothermic peak.

for samples 5 (vat bright orange KKhD), 17 (phenylfluorone), and 21 (methylene blue): 35.5, 48.4, and $28.3 \mathrm{~m}^{2} / \mathrm{g}$, respectively. The shape of the adsorption isotherms shows there were almost no micropores in the samples, so the structure of the resulting materials was closer to GC than to activated carbon.

Sample 19 (methyl orange), along with sample 17, melted with decomposition when heated in a thermal analyzer furnace $\left(10\right.$ or $\left.1^{\circ} \mathrm{C} / \mathrm{min}\right)$. They did not melt when heated more slowly in a muffle furnace $\left(0.2^{\circ} \mathrm{C} / \mathrm{min}\right)$. An interesting feature of methyl orange thermolysis upon heating at a rate of $1-10^{\circ} \mathrm{C} / \mathrm{min}$ was the formation of a porous open carbon network that resulted from the foaming of the sample (Fig. 2). The reason for this morphology was apparently the release of nitrogen during the decomposition of the diazo group. Decomposition began immediately after the onset of melting, as was reflected by the thermogram having no endothermic melting peak. It contained only the exothermic peak of the decomposition reaction (Fig. S2).

Sample 21 (methylene blue) melted completely when heated in a thermal analyzer furnace at a rate of $10^{\circ} \mathrm{C} / \mathrm{min}$. However, the smallest crystals (more than half of the sample) did not melt at a melting rate of $1^{\circ} \mathrm{C} / \mathrm{min}$, and even large crystals did not melt upon slower heating in a muffle furnace $\left(0.2^{\circ} \mathrm{C} / \mathrm{min}\right)$. This 


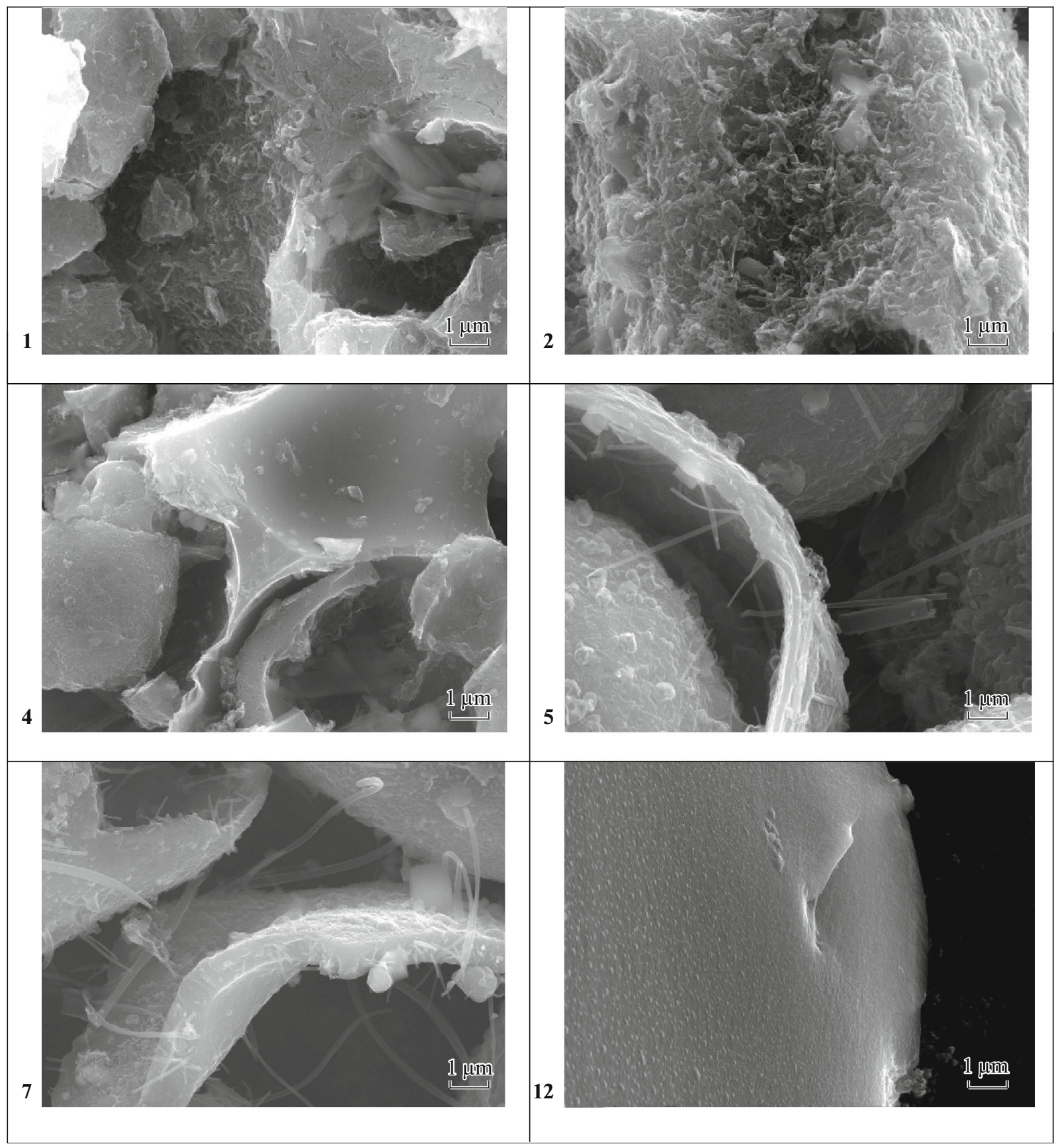

Fig. 1. Morphology of carbon materials after thermolysis in a muffle furnace at a rate of $0.2^{\circ} \mathrm{C} / \mathrm{min}$. Numbers correspond to those in Table 1. Images of sample $\mathbf{1 7}$ are shown in both the secondary and reflected electron modes.

behavior of samples $\mathbf{1 7}$ and $\mathbf{2 1}$ suggests that thermolysis starts from the surface of a crystal and gradually moves inwards. If the rate at which small fragments of molecules (e.g., water and benzene) are removed from the depth of the crystal by diffusion is higher than the rate of their formation, the liquid phase in which they participate does not form and the crystal does not melt. Similar behavior is characteristic of the crystalline hydrates of many salts that can dehydrate when heated slowly without melting, but melt when heated quickly.
The simultaneous presence of molten and unmelted material can be seen for instance in phenylfluorone heated at a rate of $10^{\circ} \mathrm{C} / \mathrm{min}$ and methylene blue heated at a rate of $1^{\circ} \mathrm{C} / \mathrm{min}$ (Fig. 2).

A specific feature of the thermolysis of diphenyldiacetylene (sample 24) is its polymerization in a melt in the range of $150-300^{\circ} \mathrm{C}$, accompanied by a release of heat (Fig. S2).

In almost all cases, X-ray phase analysis of the products of thermolysis confirmed the formation of 


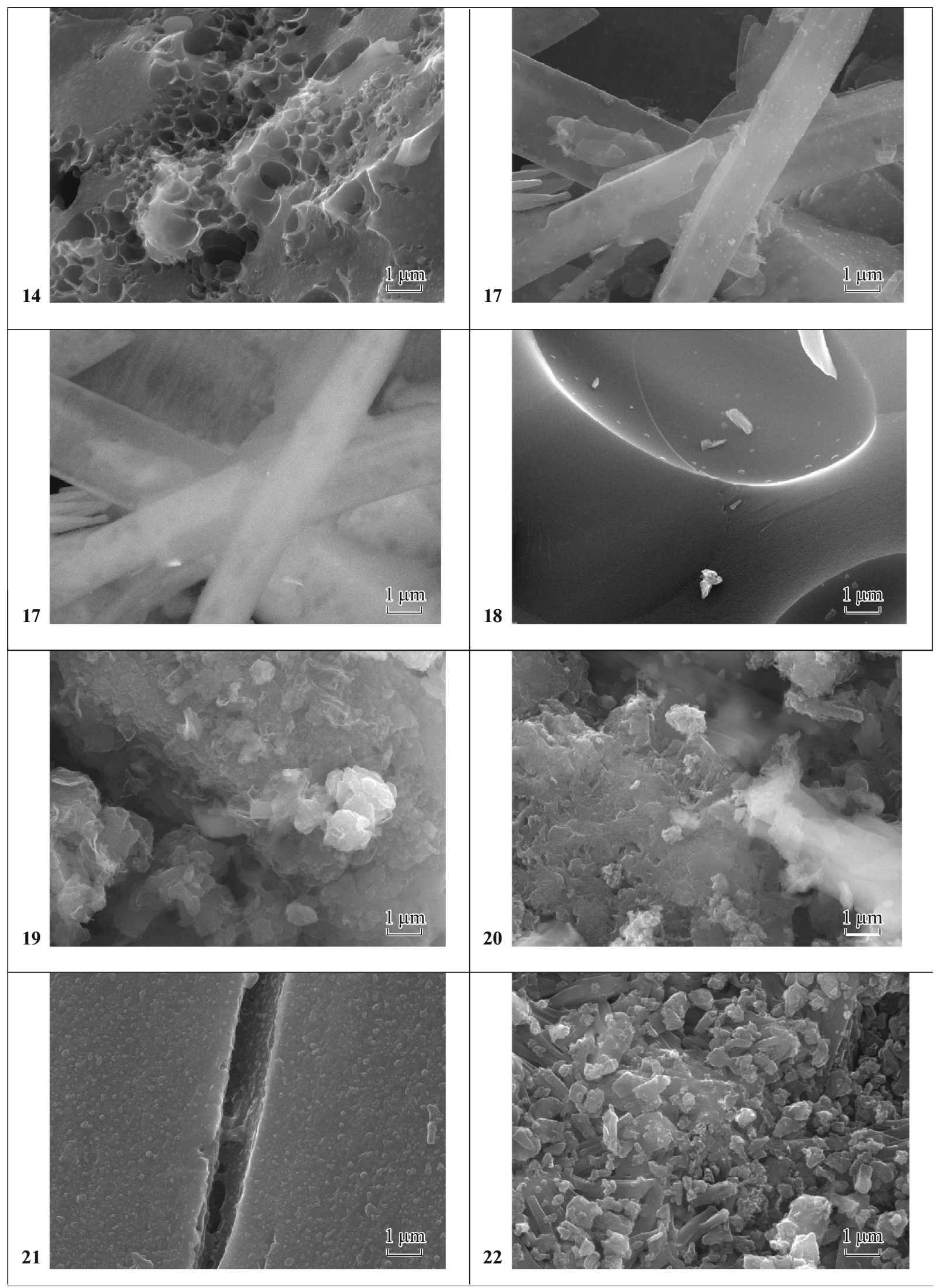

Fig. 1. (Contd.) 


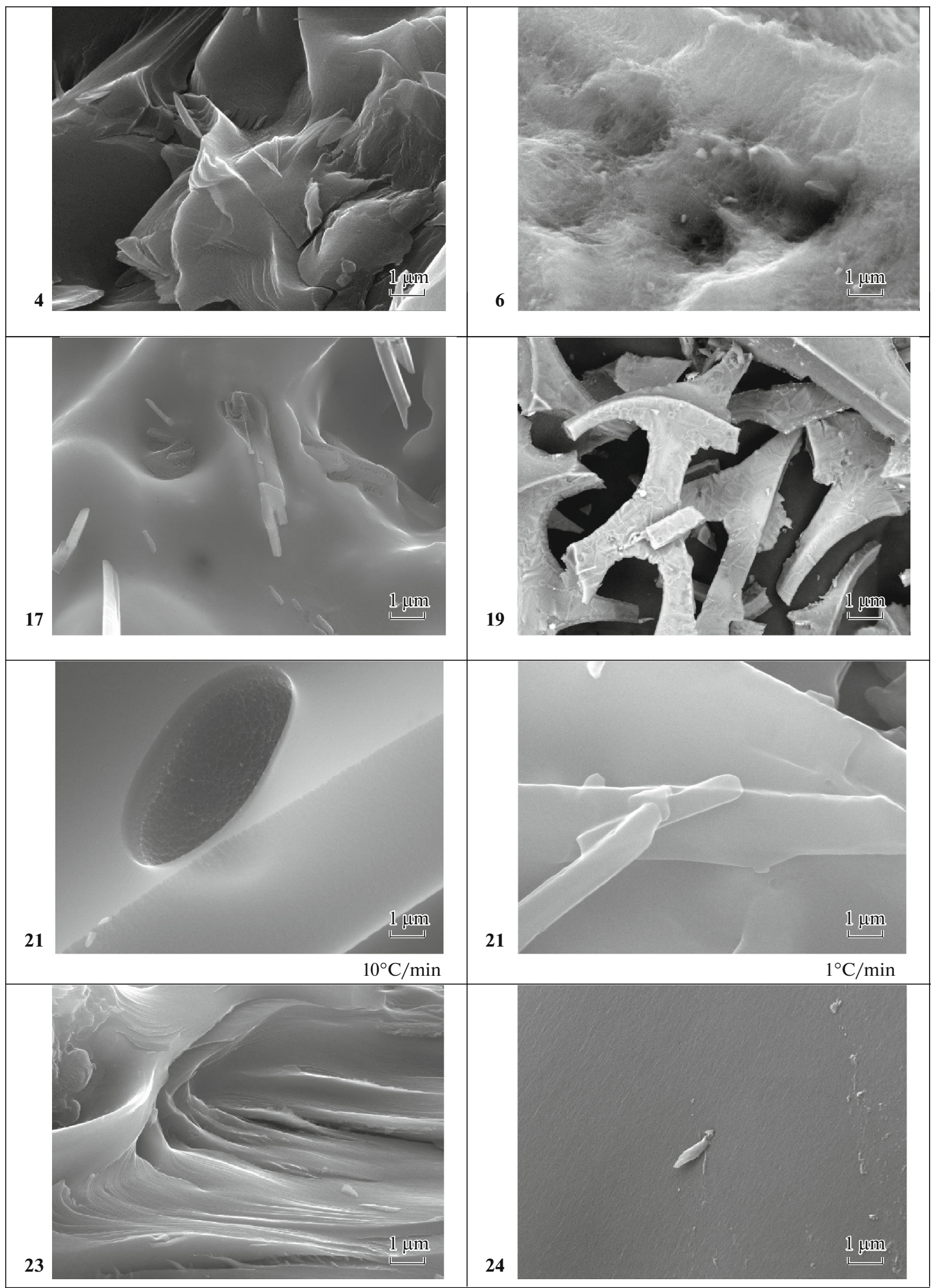

Fig. 2. Morphology of carbon materials after thermolysis in a thermal analyzer furnace at a rate of $10^{\circ} \mathrm{C} / \mathrm{min}$. Numbers correspond to those in Table 1. Suppression of the melting process at a rate of $1^{\circ} \mathrm{C} / \mathrm{min}$ is shown using the example of sample 21. 


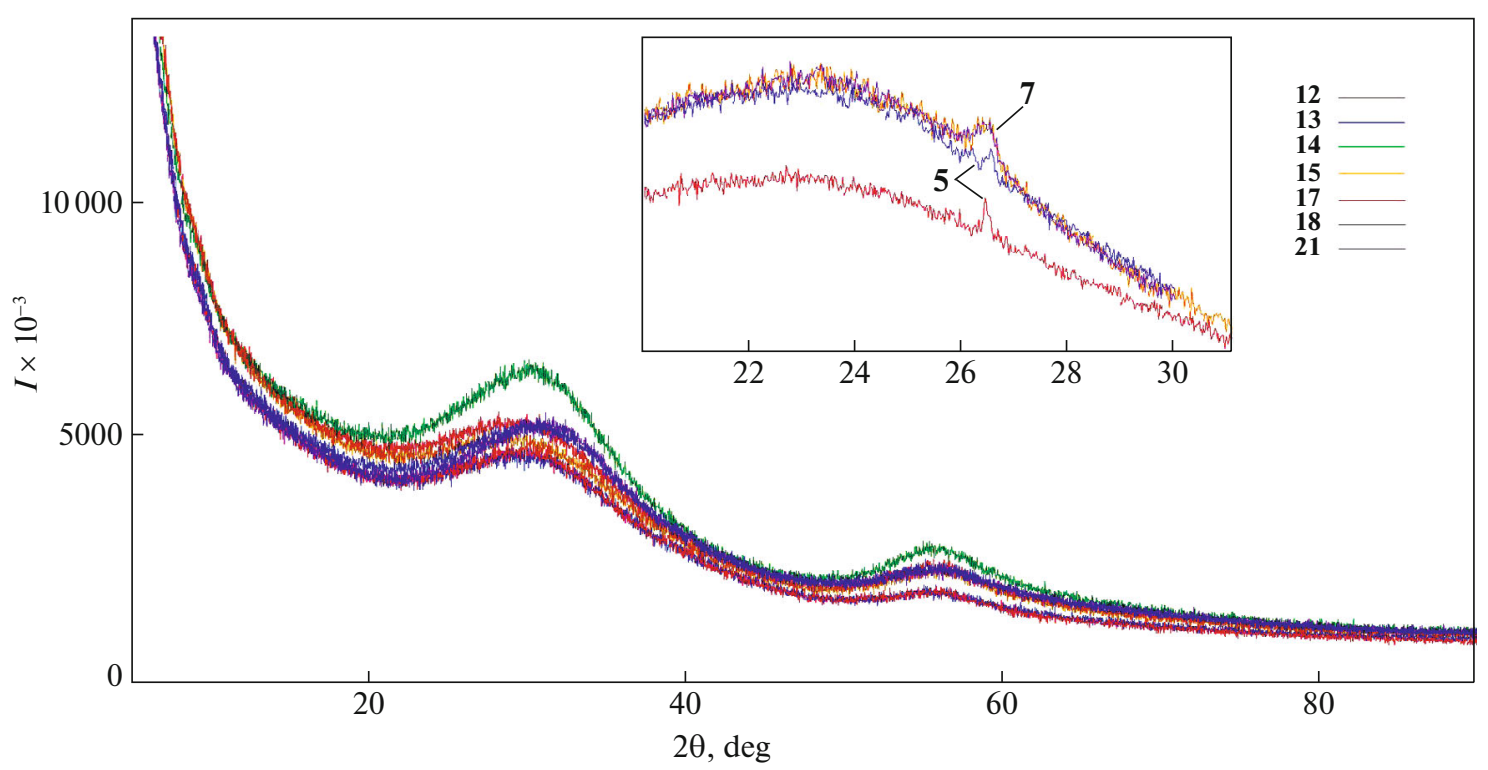

Fig. 3. Typical diffraction patterns of thermolysis products in a muffle furnace. Samples 12-15, 17, 18, and 21. Inset, graphite peak in samples 5 and 7.

only X-ray amorphous GC (Fig. 3). In sample 5 heated in the thermal analyzer furnace, we can nevertheless distinguish a weak but narrow reflection at $2 \theta \sim 26.5^{\circ}$ that can be attributed to graphite. An equally weak but broader graphite peak is also noticeable for sample 7. In both cases, the amount of graphite is at the limit of detection (no more than $1 \mathrm{wt} \%)$.

Based on our experiments, we may conclude that three factors influence the high yield of the carbon residue. The first is the high number of carbon atoms in relation to other elements, and the presence of structural features that give molecules the ability of easy polycondensation. The second is the noticeable

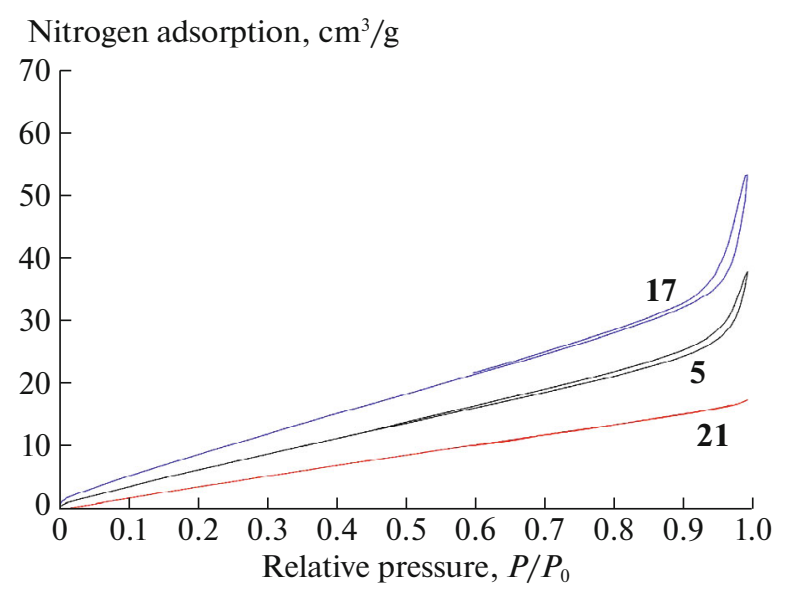

Fig. 4. Adsorption isotherms for samples 5, 17, and 21 after thermolysis in a muffle furnace. effect of the heating rate on the yield of carbon residue, due to different rates of sublimation (evaporation) and polycondensation. Sample weight has a similar effect on sublimation and evaporation. The third is the purity of the substance.

Features of the molecular structure can include the presence of halogens and hydroxyl and amino groups, which at relatively low temperatures can detach from the main molecule, initiating its condensation with neighboring molecules. In sample 1, after heating to $\sim 400^{\circ} \mathrm{C}$ in an argon atmosphere, the relative content of chlorine fell by a factor of 4 . The content of sulfur fell by $20 \%$, while the material retained virtually all of its oxygen. Polycondensation in the solid phase with the release of $\mathrm{HCl}$ was therefore the main reason for the formation of GC in sample 1 with no intermediate stage of the substance melting. Sample 25 is an example of there being no polycondensation with the release of $\mathrm{HBr}$. In the latter case, the weight reduction in the liquid phase proceeded in almost one stage at relatively low temperatures of $230-440^{\circ} \mathrm{C}$ with a loss of around $37 \mathrm{wt} \%$, which could correspond to the removal of two aliphatic bromohexyl radicals. The residue found after $1000^{\circ} \mathrm{C}$ was in satisfactory agreement with the assumption that GC formed only from carbon atoms of the aromatic nucleus.

In most cases, thermograms show only one stage of weight loss or continuous weight loss without pronounced steps, which does not allow a clear interpretation of the ongoing reactions. However, samples $\mathbf{5}$, $18,19,21$, and 24 are characterized by relatively clear steps possibly associated with the removal of certain groups and molecules. 
We may assume that with dibromantanthrone 5 , the transition of all 22 atoms of the aromatic nucleus to the solid carbon residue was the material's final state. Bromine, oxygen, and hydrogen were in this case removed as $\mathrm{HBr}, \mathrm{H}_{2} \mathrm{O}$, and $\mathrm{H}_{2}$, and the weight loss was $43.1 \mathrm{wt} \%$. The measured weight loss at $1000^{\circ} \mathrm{C}$ was $66.2 \mathrm{wt} \%$ at a $10^{\circ} \mathrm{C} / \mathrm{min}$ heating rate, and $71.2 \mathrm{wt} \%$ at a $1{ }^{\circ} \mathrm{C} / \mathrm{min}$ heating rate, which is much higher than was expected. The first and relatively low-temperature stage of the weight loss of sample 5 can be attributed not only to decomposition but to sublimation as well (as for sample 1 and some others). At a $10^{\circ} \mathrm{C} / \mathrm{min}$ heating rate, 14.0 wt $\%$ then has time to sublimate and decompose before reaching $315^{\circ} \mathrm{C}$; at a rate of $1^{\circ} \mathrm{C} / \mathrm{min}$, the figure is $9.3 \mathrm{wt} \%$ when rising to $300^{\circ} \mathrm{C}$. Weight loss terminates above this temperature, due possibly to polycondensation with the removal of one water molecule, in parallel with sublimation. The weight loss is $3.9 \mathrm{wt} \%$ when one water molecule is removed. We cannot exclude the possibility of polymerization with the cleavage of the double bonds of the carbonyl groups as a reason for the termination of sublimation. Bromine atoms do not separate from the dye molecules up to $315^{\circ} \mathrm{C}$, since the weight loss would be $17.4 \mathrm{wt} \%$ upon the removal of only one $\mathrm{HBr}$ molecule, which is much higher than the observed values.

The second stage of thermolysis likely corresponds to the removal of hydrogen bromide at $315-530^{\circ} \mathrm{C}$ with a heating rate of $10^{\circ} \mathrm{C} / \mathrm{min}$, and $300-490^{\circ} \mathrm{C}$ with a heating rate of $1^{\circ} \mathrm{C} / \mathrm{min}$. It is at this stage that most of the weight is lost, estimated at $34.9 \mathrm{wt} \%$ upon the separation of two $\mathrm{HBr}$ molecules. (The observed values were 39.5 and $42.3 \mathrm{wt} \%$ at 10 and $1{ }^{\circ} \mathrm{C} / \mathrm{min}$, respectively). The mass spectrometry of released gases could, for example, clarify the mechanism of thermolysis. It is also of interest to perform thermolysis up to $315^{\circ} \mathrm{C}$, and then examine the product via IR spectroscopy and X-ray phase and elemental analysis.

The weight loss of compound $\mathbf{1 8}$ (aluminon) in the liquid state at $200-330^{\circ} \mathrm{C}$ (observed value, $32.4 \mathrm{wt} \%$ ) is close to the one calculated for the elimination of three ammonium ions in the form of ammonia and three carboxyl groups in the form of $\mathrm{CO}_{2}(38.7 \mathrm{wt} \%)$.

With compound 19 (methyl orange), the weight loss at the first stage is almost independent of the heating rate: 21.8 and $21.5 \mathrm{wt} \%$ at 10 and $1^{\circ} \mathrm{C} / \mathrm{min}$, respectively (up to 390 and $355^{\circ} \mathrm{C}$ ). The obvious conclusion that the azo group in the form of $\mathrm{N}_{2}$ is removed corresponds to a loss of only $8.6 \mathrm{wt} \%$. We must therefore assume that dimethylamine is eliminated at the same time as this process, leading to a loss of $22.3 \mathrm{wt} \%$. We may conclude that at $1000^{\circ} \mathrm{C}, \mathrm{Na}_{2} \mathrm{~S}_{2}$ and carbon form as end products from 12 aromatic carbon atoms. This model corresponds to a loss of $39.2 \mathrm{wt} \%$, but the true losses are 73.3 and $79.4 \mathrm{wt} \%$ at heating rates of 10 and $1{ }^{\circ} \mathrm{C} / \mathrm{min}$, respectively. The formation of $\mathrm{Na}_{2} \mathrm{~S}_{2}$ and carbon from 6 aromatic carbon atoms corresponds to a loss of $61.2 \mathrm{wt} \%$, which is closer to the experimental value.
For sample 21 (methylene blue), we may assume 12 atoms of the aromatic ring transform into a solid carbon residue. Chlorine, sulfur, nitrogen, water, and hydrogen are then released as $\mathrm{HCl}, \mathrm{H}_{2} \mathrm{~S}$, dimethylamine, $\mathrm{N}_{2}, \mathrm{H}_{2} \mathrm{O}$, and $\mathrm{H}_{2}$ with a loss of $61.4 \mathrm{wt} \%$. This is in complete agreement with the measured weight loss at $1000^{\circ} \mathrm{C}: 55.1$ and $65.4 \mathrm{wt} \%$ at heating rates of 10 and $1^{\circ} \mathrm{C} / \mathrm{min}$, respectively.

Compound 24 (1,4-diphenylbutadyine-1,3 or diphenyldiacetylene) in the liquid state evaporates (46.4 wt \% weight loss) and polymerizes at $88-310^{\circ} \mathrm{C}$, as is apparent from the termination of weight loss at around $310^{\circ} \mathrm{C}$. In contrast to other diacetylenes [6], this polymer has another large step of weight loss of $16.2 \mathrm{wt} \%$ at around $310-610^{\circ} \mathrm{C}$.

When calculating the expected GC residue (Table 2), it was assumed that after heating to high temperatures (up to, e.g., $2000^{\circ} \mathrm{C}$ ), all aromatic carbon atoms of the initial molecules would remain in the carbon residue, and all other atoms would be removed in the form of carbon-free molecules: $\mathrm{H}_{2} \mathrm{O}, \mathrm{HCl}, \mathrm{HBr}, \mathrm{H}_{2} \mathrm{~S}, \mathrm{~N}_{2}$, and $\mathrm{NH}_{3}$. The methyl groups of sample $\mathbf{1}$ are in this case presumably removed in the form of methane and ethane.

Sublimation from the solid phase and evaporation of the melt are processes that compete with polycondensation. When vat dyes of technical grade were slowly heated in a muffle furnace, the carbon yields were higher than during the relatively rapid heating of purified dyes in a thermal analyzer oven (Table 2 ). In contrast, lowering the heating rate from 10 to $1^{\circ} \mathrm{C} / \mathrm{min}$ in the thermal analyzer furnace reduced the yield of carbon considerably, due to the sublimation of small portions at relatively low temperatures where condensation was still weak. Raising the weight of a sample in the muffle furnace to 50-150 mg increased the yield of carbon, since the rate of entrainment of the substance's vapor at low weights makes a stronger contribution.

Pitch is a good example of competition between evaporation and polycondensation. Thermograms of pitch at heating rates of 0.5 and $10^{\circ} \mathrm{C} / \mathrm{min}$ in a nitrogen atmosphere at a pressure of $1 \mathrm{~atm}$ show that slower heating results in a lower yield of coke [15], due to the evaporation of relatively more volatile components below $400^{\circ} \mathrm{C}$. In contrast, raising the nitrogen pressure to 55 atm during heating suppresses the evaporation of these components and increases the yield of coke, due to their participation in polycondensation reactions.

Polycondensation can occur in a solid crystal at temperatures below its melting point (samples 1, 5, and $\mathbf{1 7}$ according to data from thermal analysis).

As noted in [13], the purity of the initial compound can affect the yield of carbon: a purer substance is evaporated or sublimed to a greater extent during heating, while a less pure substance begins to polymerize at the same temperatures, due to the catalytic effect of impurities (e.g., iron and copper). After purification via recrystallization, the vat dyes in this work therefore had much 
higher losses at relatively low temperatures (due to sublimation and evaporation) during thermal analysis.

The results from our study are in good agreement with reported examples of the decomposition of polycyclic aromatic hydrocarbons with melting at rapid heating and without melting at slow heating [8]. At a heating rate of $0.2-0.5^{\circ} \mathrm{C} / \mathrm{min}$, we can in some cases carbonize substances without their melting. This is true in particular for compounds $3,4,6,17,19$, and 21 that melt at $468,471,375,437,369$, and $175^{\circ} \mathrm{C}$ when heated at a rate of $10^{\circ} \mathrm{C} / \mathrm{min}$. The thermolysis (decomposition) of aromatic compounds in the solid phase is therefore already developing rapidly in the $175-470^{\circ} \mathrm{C}$ range of temperatures. Phenolphthalein and aluminon (which have relatively low melting points, 263 and $224^{\circ} \mathrm{C}$ ) at a heating rate of $0.2^{\circ} \mathrm{C} / \mathrm{min}$ thus do not have time to undergo thermolysis in the solid phase; neither do structurally related compounds with relatively low molecular weights and low melting points. Xylenol orange $\left(222^{\circ} \mathrm{C}\right)$, thymolphthalein $\left(248-252^{\circ} \mathrm{C}\right)$, bromothymol blue $\left(200-208^{\circ} \mathrm{C}\right)$, bromophenol blue $\left(279^{\circ} \mathrm{C}\right)$, and crystal violet $\left(215^{\circ} \mathrm{C}\right.$ decomp.) thus have relatively low melting points, according to literature data [16-20]. As a consequence, these compounds decompose with melting even at a heating rate of $0.2^{\circ} \mathrm{C} / \mathrm{min}$.

Nevertheless, only $\mathrm{X}$-ray amorphous products formed in all of our studied cases, even during decomposition in the solid phase. We must apparently increase the size of polycyclic aromatic molecules to several dozen conjugated rings in order to avoid a catastrophic collapse of molecules during the breakage of $\mathrm{C}-\mathrm{H}$ bonds with the formation of $\mathrm{C}^{\bullet}$ radicals, intramolecular rearrangement of the carbon-carbon bond system, and subsequent chaotic binding of molecules and radicals to one another during condensation in the crystal.

We found the slow heating of many substances at a rate of $1^{\circ} \mathrm{C} / \mathrm{min}$ results in partial thermolysis of a pure substance even before it melts with the emergence of new substances (products of decomposition) in the system, which lowers the measured melting point by $18-40^{\circ} \mathrm{C}$ (samples 17, 19, and 21). From the viewpoint of correctly determining melting points, it is obvious that relatively high heating rates should be used (e.g., $10^{\circ} \mathrm{C} / \mathrm{min}$ ). At low heating rates, some substances show complete transition from melting with decomposition to decomposition in the solid state.

The heating rate can also dramatically change the quantitative characteristics of weight loss at different stages.

\section{CONCLUSIONS}

General features of the thermolysis of aromatic compounds with the formation of glassy carbon were identified and discussed. At a low heating rate, a number of substances carbonize without melting, especially if the latter occurs above $370^{\circ} \mathrm{C}$. The formation of a nanosized layered texture of porous carbon resi- due during the decomposition of phenylfluorone in the solid phase indicates a certain preferred spatial direction of condensation of neighboring molecules and allows us to consider the slow thermolysis of heavy polycyclic aromatic compounds as a promising way of obtaining new crystalline forms of carbon. Thermograms of several compounds widely used in analytical chemistry were obtained for the first time and are of practical interest. Disagreements between reference data on the melting points of substances and the nature of their thermolysis could be largely due to different heating rates, so it is desirable to indicate heating rate along with the melting point.

\section{FUNDING}

This work was supported by the Russian Foundation for Basic Research, project nos. 20-33-90094 (S.A. Nayfert) and 20-33-90095 (M.A. Polozov).

\section{ACKNOWLEDGMENTS}

Elemental and phase analyses and microscopic studies were performed at the Nanotechnology Research and Education Center of South Ural State University.

\section{CONFLICT OF INTEREST}

The authors declare that they have no conflicts of interest.

\section{SUPPLEMENTARY MATERIALS}

Supplementary materials are available for this article at available at https://doi.org/10.1134/S0036024421120232 for authorized users.

\section{OPEN ACCESS}

This article is licensed under a Creative Commons Attribution 4.0 International License, which permits use, sharing, adaptation, distribution and reproduction in any medium or format, as long as you give appropriate credit to the original author(s) and the source, provide a link to the Creative Commons license, and indicate if changes were made. The images or other third party material in this article are included in the article's Creative Commons license, unless indicated otherwise in a credit line to the material. If material is not included in the article's Creative Commons license and your intended use is not permitted by statutory regulation or exceeds the permitted use, you will need to obtain permission directly from the copyright holder. To view a copy of this license, visit http://creativecommons.org/licenses/by/4.0/.

\section{REFERENCES}

1. J. Gibson, M. Holohan, and H. L. Riley, J. Chem. Soc., 456 (1946).

https://doi.org/10.1039/JR9460000456

2. R. Hoffmann, T. Hughbanks, M. Kertesz, and P. H. Bird, J. Am. Chem. Soc. 105, 4831 (1983). 
3. M. J. Bucknum and R. Hoffmann, J. Am. Chem. Soc. 116, 11456 (1994).

4. M. Belenkov and V. A. Greshnyakov, Phys. Solid State 57, 1253 (2015).

5. Q. Y. Li, Y. F. Yao, G. Qiu, et al., Chin. Sci. Bull. 61, 2688 (2016).

https://doi.org/10.1360/N972016-00462

6. R. S. Jordan, Y. L. Li, C.-W. Lin, et al., J. Am. Chem. Soc. 139, 15878 (2017).

7. A. V. Talyzin, S. M. Luzan, K. Leifer, et al., J. Phys. Chem. C 115, 13207 (2011).

https://doi.org/10.1021/jp2028627

8. W. Boenigk, M. W. Haenel, and M. Zander, Fuel 74, 305 (1995). https://doi.org/10.1016/0016-2361(95)92671-R

9. H. B. Wu and X. W. Lou, Sci. Adv. 3, eaap9252 (2017). https://doi.org/10.1126/sciadv.aap9252

10. M. A. Polozov, S. A. Naifert, and V. V. Polozova, et al., Vestn. YuUrGU, Ser. Khim. 11 (2), 39 (2019).

11. C. Sakthi, P. Dharan, M. A. Polozov, V. V. Polozova, et al., Russ. J. Phys. Chem. A 94, 1311 (2020). https://doi.org/10.1134/S0036024420070250
12. D. A. Zherebtsov, S. A. Naifert, and M. A. Polozov, et al., Vestn. YuUrGU, Ser. Khim. 9 (4), 41 (2017). https://doi.org/10.14529/chem170406

13. D. A. Zherebtsov, M. U. Schmidt, R. Niewa, et al., Acta Crystallogr., B 75, 384 (2019). https://doi.org/10.1107/S2052520619003287

14. D. A. Zherebtsov, S. A. Nayfert, M. A. Polozov, et al.,Crystallogr. Rep. 63, 1110 (2018). https://doi.org/10.1134/S1063774518070283

15. V. E. Privalov and M. A. Stepanenko, Coal Tar Pitch (Metallurgiya, Moscow, 1981) [in Russian].

16. Chemical Encyclopedia, Ed. by I. L. Knunyants (Sov. Entsiklopediya, Moscow, 1988), Vol. 1 [in Russian].

17. Chemical Encyclopedia, Ed. by I. L. Knunyants (Sov. Entsiklopediya, Moscow, 1990), Vol. 2 [in Russian].

18. Chemical Encyclopedia, Ed. by I. L. Knunyants (Bol'sh. Ross. Entsiklopediya, Moscow, 1992), Vol. 3 [in Russian].

19. Chemical Encyclopedia, Ed. by N. S. Zefirov (Bol'sh. Ross. Entsiklopediya, Moscow, 1995), Vol. 4 [in Russian].

20. Chemical Encyclopedia, Ed. by N. S. Zefirov (Bol'sh. Ross. Entsiklopediya, Moscow, 1998), Vol. 5 [in Russian].

Translated by G. Levit 